\title{
NO SE VE, NO SE TOCA Y SIN EMBARGO, EXISTE: LA ESCLAVITUD HOY. HACIA UNA RECONCEPTUALIZACIÓN DEL TRABAJO ESCLAVO
}

\author{
Mikel Urrutikoetxea Barrutia \\ Universidad del País Vasco/Euskal Herriko Unibertsitatea
}

Orcid: 0000-0003-0295-3254

Recibido el 30 de septiembre de 2016

DOI: $10.1387 /$ lan-harremanak. 17503

Aceptado el 11 de noviembre de 2016.

\section{ABSTRACT}

Resumen: En este trabajo abordamos la cuestión de la esclavitud hoy. Para ello empezamos confrontando ciertos mitos sobre la misma, para a continuación aproximarnos a la importancia del fenómeno y a las formas que presenta hoy, matizando las diferencias entre la esclavitud tradicional y la contemporánea. Seguidamente analizamos los conceptos de esclavitud, trabajos forzados y servidumbre a la luz de las normas internacionales, asi como las diferencias que existen entre estos conceptos. Posteriormente, nos dirigimos al derecho interno para acercarnos a las disposiciones sobre este fenómeno presentes en el Derecho español y tras constatar la ausencia de tipificación como delito del trabajo esclavo o el forzado, puntualizamos la diferencia entre explotación laboral y los trabajos coactivos. $Y$ concluimos con un reconceptualización del trabajo coactivo que posibilite una intervención más eficaz sobre las formas contemporáneas de trabajo esclavo.

Palabras clave: esclavitud, trabajos forzados, servidumbre.

Abstract: In this paper we approach the issue of slavery today. To do this we begin by confronting some myths about it, and then we asses the importance of the phe- 
nomenon and the ways it presents today, clarifying the differences between traditional and contemporary slavery. Then we analyze the concepts of slavery, forced labor and servitude in the light of international norms, as well as the differences that exist between these concepts. Subsequently, we turn to internal law to aboard the provisions on this phenomenon present in Spanish law and after to note the absence of criminalization of slave or forced labor, we point out the difference between labor exploitation and coercive works. And we conclude presenting a new concept of coercive work that makes possible a more effective intervention on contemporary forms of slave labor.

Keywords: slavery, forced labour, servitude.

Laburpena: Artikulu honetan gaur eguneko esklabotza jorratuko dugu. Horretarako horri buruzko mito batzuk berrikusten hasiko gara. Ondoren, fenomenoaren garrantzia eta gaur agertzeko bideetara hurbilduko gara, esklabotza tradizionala eta garaikidea ezberdinduz. Gero esklabotza, lan bortxatuak eta morrontza kontzeptuak aztertuko ditugu nazioarteko arauen arabera eta, era berean, kontzeptu horien arteko desberdintasunak argitzen saiatuko gara. Une horretan, barneko legedira joko dugu eta lan esklabo eta edo lan behartuaren kriminalizazio eza egiaztatu ondoren, lan-esplotazioa eta bortxazko lanaren arteko aldea azpimarratuko dugu. Eta bukatzeko, lan behartuaren kontzepzio berria aurkeztuko dugu, gaur eguneko esklabotzaren formen kontra eraginkorragoa izan daitekeelakoan.

Hitz gakoak: esklabotza, lan bortxatuak, morrontza. 


\section{SUMARIO}

Sumario 1. Introducción. 2. Imagen distorsionada de la esclavitud. 3. Manifestaciones del trabajo esclavo en la actualidad. 4. Diferencias entre la esclavitud tradicional y la actual. 5. Concepto de esclavitud, trabajo forzoso, diferencias y matices entre esclavitud, trabajo forzoso y servidumbre. 5.1. Concepto de esclavitud y de otras formas de trabajo coactivas en las normas internacionales. 5.2 Diferencias y matices entre esclavitud, trabajo forzoso y servidumbre. 6. Esclavitud y trabajo esclavo en el derecho interno. 7. Reconceptualizacion del trabajo esclavo a efectos laborales. 8. Bibliografía.

\section{Introducción}

Como recuerda Rodríguez-Piñero el Derecho de Trabajo ha prestado una sistemática desatención hacia las formas de trabajo obligatorio (2011: 306); al circunscribir su reflexión al trabajo libre, la esclavitud quedaba fuera de sus fronteras disciplinares y ha tendido a ignorarla. De manera coincidente con este autor, nosotros también creemos que es necesario integrar en el análisis del trabajo el estudio de las formas anómalas del trabajo dependiente. Nuestra visión sobre las relaciones laborales sería incompleta sin incorporar esas formas de trabajo esclavo y coactivo. Además, el incremento de estas formas de trabajo coactivas es también una de las consecuencias obscuras de la globalidad y, se produzca donde se produzca, el trabajo esclavo presiona a la baja todas las condiciones de empleo, pues las empresas beneficiarias son multinacionales globalizadas. Luchar contra el trabajo coactivo es siempre una forma de mejorar las relaciones laborales en su conjunto.

Sin embargo, debemos hacer un esfuerzo extra, pues una de las características de la esclavitud en nuestra época es que resulta imperceptible, se esconde y disimula su naturaleza. En diferentes análisis o reflexiones sobre el trabajo esclavo o los servicios coactivos se destaca la invisibilidad del fenómeno (incluso en el propio título del informe del Defensor del Pueblo sobre la trata de seres humanos se destaca esta característica $\left.{ }^{1}\right)$. Cómo dice Casadei (2009: 177) «...la

1 También puede encontrarse una aseveración parecida, incluso, en las propias normas jurídicas. Así, por ejemplo, en la California Transparency in Supply Chains Act of 2010 se afirma que: «As a result of the criminal natures of slavery and human trafficking, these crimes are often hidden from view and are difficult to uncover and track». 
esclavitud en los paises occidentales no se ve, no se toca, por lo tanto no existe,...". Debemos, por tanto, sacarla de la obscuridad y darle nombre.

El presente trabajo lo comenzamos cuestionando la imagen distorsionada sobre la esclavitud que a veces creamos entre todos, y seguido damos paso a una mínima exposición sobre las manifestaciones del trabajo esclavo en la actualidad y las diferencias con la esclavitud tradicional.

Luego, analizamos los conceptos de esclavitud, servidumbre y trabajos forzados en las normas internacionales, así como las diferencias y matices que existen entre ellos. Posteriormente, nos dirigimos al derecho interno para acercarnos a las disposiciones sobre este fenómeno presentes en el Derecho español $y$, tras constatar la ausencia de tipificación como delito del trabajo esclavo o el forzado, puntualizamos la diferencia entre explotación laboral y los trabajos coactivos. Y concluimos con una reconceptualización del trabajo coactivo que posibilite una intervención más eficaz sobre las formas contemporáneas de trabajo esclavo.

Dada la naturaleza del tema que abordamos, además de las fuentes habituales en un artículo jurídico, hemos creído necesario acudir a otras como los periódicos o las web de ONGs que inciden en el trabajo esclavo; dado la opacidad del trabajo coactivo y su actualidad son estos testimonios los que nos permiten conseguir un cierto redimensionamiento del trabajo esclavo ${ }^{2}$.

\section{Imagen distorsionada de la esclavitud}

Al examinar la esclavitud a veces caemos en simplificaciones o en falacias, falsas representaciones que limitan su compresión, pues restringen la actualidad o la complejidad de esta figura.

Todos somos participes de la creación de una imagen distorsionada o simplificada de la esclavitud. En nuestras exposiciones en clase, la vinculamos al estatus, sin conexión posible con el ánimo contractual, la visualizamos como una situación de carácter permanente y anclada a un modo de producción ya superado. Es frecuente que presentemos la esclavitud como algo opuesto al trabajo asalariado ${ }^{3}$, un

\footnotetext{
2 De hecho, cuando terminamos de escribir este artículo la noticia en los medios es la liberación de 34 esclavos búlgaros en Cuellar (Segovia) y Sueca (Valencia), obligados a trabajar en labores agrícolas (Tribuna de Valladolid, 2.11.2016).

3 Por citar un ejemplo de un autor calificado, Montoya (2011: 55) afirma que "Juridicamente, el esquema de la relación dueño-esclavo está en las antipodas de la moderna vinculación empresariotrabajador; si el trabajador contemporáneo es una persona que contrata voluntariamente la prestación de su trabajo, el esclavo no es reputado persona, y por tanto carece de la posibilidad de prestar su consentimiento".
} 
estadio previo a la generación de esta forma de trabajo dependiente y erradicada por la abolición.

Sin embargo, esta no es necesariamente toda la verdad, ni agota la complicidad del trabajo esclavo o coactivo. Así, por ejemplo, gran parte de lo colonización de la America septentrional se efectuó con los indentured servants o siervos por contrato (Williams, 2011: 36) en donde, a cambio del pago del pasaje transatlántico, se comprometían a trabajar como siervos por un tiempo de determinado; en definitiva, un contrato para trabajar como esclavo temporal para pagar la deuda que ha posibilitado su cambio de continente ${ }^{4}$. Las similitudes con prácticas actuales son evidentes, si bien hoy se visualizan como trata de seres humanos y servidumbre por deudas ${ }^{5}$. También fueron objeto de trabajo sometido a sujeción los convicts servants y los deportados políticos o religiosos sometidos a un menor plazo de sujeción, normalmente (Moulier-Boutang, 1998: 233 y 239$)$.

En cuanto a la temporalidad, en nuestra retina la esclavitud se asimila al modelo que enlaza con la trata transoceánica, donde se nace esclavo y se muere esclavo y donde la piel marca la frontera de la esclavitud, pero en realidad en el concepto de esclavitud se incluyen supuestos muy heterogéneos, desde prácticas ancestrales de heterodisponibilidad de la persona a situaciones modernas de explotación de poblaciones vulnerables (Rodriguez Piñero, 2011a: 311).

En la propia Biblia, por ejemplo, se contempla una forma de esclavitud que conlleva la liberación del esclavo al séptimo año de esclavitud tras la compra del esclavo (Éxodo, XXI. 2, y Deuteronomio XV, 12-18) o se admite la venta de la propia hija como esclava (Éxodo XXI.7).

Como veremos, de la propia definición internacional se desprende que la esclavitud encierra diferentes situaciones de dominio y cosificación, según las épocas y contextos económicos y cultura, de ahí que se precise que los derechos de propiedad que se ejerza sobre el esclavo puedan ser algunos de los que se comprenden en la propiedad y no siempre todos ellos.

La abolición se presenta como un fenómeno culminado con rapidez, pero en realidad fue un proceso tortuoso, que ha durado casi 2 siglos entre el pri-

\footnotetext{
${ }^{4}$ Existía otra modalidad, los redemptioner, que si no pagaban el viaje en un plazo determinado se comprometían a ser vendidos al mejor postor como esclavos por un periodo de tiempo (Williams, 2001: 37).

5 Aunque esta situación suponía que el amo ejerciera derechos de propiedad sobre los indetured servants, Bush (2000: 237) matiza que si bien la esclavitud equivalía a la muerte social, esta otra situación así como la servidumbre penal, suponían una especie de periodo de letargo social, en el cual los trabajadores están temporalmente fueran de la condición de personas, pero la volvía a adquirir al finalizar esa situación.
} 
mero y último estado que abolieron la esclavitud ${ }^{6}$. España es un ejemplo más de que la abolición de la esclavitud se retrasó en aquellos territorios donde la misma poseía una importancia económica determinante. De hecho, el proceso de abolición en el estado español fue singularmente proceloso y gradual, siendo las posesiones americanas de España uno de los territorios americanos donde la abolición se demoró más (solo fue más tardía en Brasil), no culminándose el proceso de abolición hasta 18867 .

Además, tras los procesos de abolición se mantuvo la necesidad de mano de obra masiva y barata que fue cubierta con diversas formas de trabajo forzoso y servidumbre; Alonso (2002: 347) señala la pervivencia de un «nuevo sistema de esclavitud» representado por las indentures, pseudocontratos de trabajo con exportación del trabajador sometido a trabajo servil ${ }^{8}$. La misma tesis se mantiene en la obra Slavery by another name de Douglas A. Blackmon, ${ }^{9}$ donde el recurso al trabajo penal (convict lease labor) o al peonaje de los afroamericanos, conformó un nuevo tipo de servidumbre tras la abolición de la esclavitud en EEUU al finalizar la guerra civil ${ }^{10}$.

Pensar que la abolición de la esclavitud acarrea su erradicación de las relaciones sociales supone una enorme mistificación de lo jurídico. La percepción de que el mundo jurídico es el único origen de la obligatoriedad en las relaciones sociales no es acertada. Como afirma García (2014: 2072) «...el trabajo libre nunca sustituyó totalmente al trabajo esclavo, pues subsisten diversas formas diferentes de explotación del trabajo que se complementan en el sistema capitalista». Frente a una visión simplista que empareja la esclavitud con un modo

6 El primer territorio que proclamó la abolición fue Haiti; en el contexto de una guerra de liberación de los esclavos en 1793 el comisionado francés intentó así ganar adeptos. Poco más tarde fue abolida en Francia el el 4 de febrero de 1794, pero en ambos casos Napoleón restauró la esclavitud. El último fue Mauritania que la abolió por decreto de 5 de julio de 1980, y entró en vigor a principios de 1981 (Lengellé-Tardy, 2002: 3).

7 Mientras que en los territorios peninsulares la abolición se reguló en la Ley de 5 de marzo de1837, en las colonias se retrasó a 1870 para Puerto Rico (Leyes de 4 de julio de 1870 y de 22 de marzo de 1873) y una década más para Cuba (Ley de 13 de febrero de 1880 y RD de 7 de octubre de 1886).

8 Nos comenta este autor el lugar reseñado que este sistema se utilizó para enviar miles y miles de personas desde la India a otras zonas del imperio, como Ceylán o el Caribe.

9 El título complementario es significativo; The Re-Enslavement of Black Americans from the Civil War to World War II. La obra, publicada en 2008, obtuvo el premio Pulitzer. En 2012 se elaboró un film con esa misma denominación, asequible en internet en http://www.pbs.org/tpt/slavery-byanother-name/watch/.

10 Es pertinente recordar que la $13 .^{\mathrm{a}}$ enmienda de la Constitución de EEUU abolía la esclavitud y la servidumbre, excepto como castigo de un delito que haya sido declarado responsable; "Neither slavery nor involuntary servitude, except as a punishment for crime where of the party shall have been duly convicted, shall exist within the United States, or any place subject to their jurisdiction». En el documental 13th se sostiene que la utilización de la fisura de la $13 .{ }^{a}$ enmienda posibilitó el mantenimiento de los ex-esclavos como mano de obra sometida a sujeción a través de diversos sistemas (convict lease, peonage, leyes Jim Crow, mass incarceration...) y que ha generado una subordinación étnica 
de producción ya pasado, se puede mantener con Lengellé-Tardy (2002: 10) que la esclavitud es inherente al progreso económico $y$, como firma este autor, cada etapa de liberación del trabajo lleva el germen de una nueva forma de servidumbre (2002: 12).

\section{Manifestaciones del trabajo esclavo en la actualidad}

Cuantificar la esclavitud, el trabajo bajo sujeción, es difícil. En la actualidad es una práctica en las sombras, clandestina, amparada bajo otro nombre: «el esclavo - en la época de la globalización,... es invisible a los ojos de la ley, como a los ojos de la sociedad y del mundo (Casadei, 2009: 173). Contar lo oculto, lo que se esconde deliberadamente, es una tarea ardua y compleja.

De ahí que las cifras sobre la esclavitud sean resbaladizas y que varíen enormemente según las fuentes ${ }^{11}$. La OIT estima en unos 21 millones las personas sometidas a trabajo forzoso (ILO, 2012: 1) ${ }^{12}$, mientras que otras fuentes elevan la cifra de esclavos a 46 millones en el año 2016 (Walk free Foundation, 2016: $4^{13}$ ). La incertidumbre de los datos se resalta si recordamos que en el informe anterior de la OIT, de 2005, se cifró en 12,3 millones las víctimas de trabajo forzoso ${ }^{14}$.

Las estimaciones para España incluidas incluidas en The Global Slavery In$\operatorname{dex}$ (2016: 29), 8400 personas, nos parecen excesivamente bajas ${ }^{15}$. Si ponderamos que, según el informe sobre la trata y la prostitución elaborado por las $\mathrm{Na}$ ciones Unidas (2010: 9) una de cada 7 de las prostitutas esta sometida a la trata con esa finalidad coactiva y que las cifras de prostitución se suelen situar por encima de las 300.000 personas, la hipótesis de al menos 20.000 personas sometidas al tráfico de seres humanos en este ámbito no parece excesiva. Téngase en cuenta que el periodo de explotación según el informe es de 2 años (Naciones Unidas, 2010: 9), por lo que la rotación y la inserción de nuevas personas en la trata es constante. Además, según la ONG Free the Slave, el $22 \%$ de los escla-

11 Bales cifraba en unos 27 millones el número de esclavos a finales del siglo xx (Bales, 2000b: 9).

12 La inmensa mayoría es explotada en la economía privada $(90 \%)$, y el $55 \%$ son mujeres o niñas. El informe cualifica en un millón y medio las personas en esta situación en las economías desarrolladas incluida la Unión Europea.

13 En The Global Slavery index se cifra en 45,8 la población sometida a esclavitud o servidumbre, reuniéndose el $58 \%$ de esa cifra en 5 países: India, China, Pakistan, Uzbekistán y Bangladesh.

14 En cualquier caso, ambas estimaciones de la OIT se basan en el método de recopilación de casos denunciados, por lo que es obvio que se trata de una estimación a la baja, que identifica un número mínimo (ILO, 2012: 5).

15 Las cifras parecen especialmente optimistas en este caso, inferiores a los países del entorno como Portugal o Francia y muy por debajo de las correspondientes a países de tamańo similar como Italia $(129,600)$ o Polonia $(181,100)$. 
vos realiza servicios de naturaleza sexual, mientras que el $68 \%$ efectúa otro tipo de trabajos de forma coactiva (el $10 \%$ restante presta sus servicios obligatorios al Estado). De hecho, las estimaciones de Médicos Mundi en 2012 cifraban en 50.000 las personas sometidas a la trata de seres humanos en España compelidas a efectuar trabajos coactivos o sometidas a explotación sexual o delictiva $(A B C$, 21/12/201).

En realidad, la esclavitud, el trabajo forzoso o sometido a sujeción, y el trabajo asalariado no son dos mundos ajenos. Antes bien al contrario, se puede plantear que el dominio pleno de una persona por otra, con negación absoluta de los derechos del esclavo (incluso los inherentes a su personalidad) y el trabajo asalariado son diferentes graduaciones o extremos del trabajo dependiente ${ }^{16}$. Existe una inclinación hacia la compulsión y la coercitividad del trabajo que varían en función del contexto y las circunstancias.

Por supuesto, la motivación ultima del uso de trabajo coactivo es económica, claro; la OIT sostiene que el trabajo forzado origina unos 150.000 millones de dólares anuales y por cada individuo sometido a este tipo de trabajo coactivo se generan unos 34.000 dólares anuales en las economías desarrolladas y Europa (ILO, 2014: 13 y 14).

Más allá de este hecho hay, a nuestro entender, cuatro ejes que presionan para que se origen formas de trabajo coactivo con limitaciones de la libertad del trabajador:

1. asegurar el suministro de mano de obra

2. reducción de costes (e intensificación de la explotación)

3. una matriz disciplinaria

4. la articulación de un doble mercado (exógeno/endógeno).

Las dos primeras motivaciones laten en la generalización de la mano de obra esclava en los cultivos coloniales entre los siglos XVI y XIX, y en la fortaleza de la trata de esclavos durante estos ańos. Incluso estas mismas razones explican la utilización de otras fórmulas de trabajo sometido a sujeción, tras la abolición de la esclavitud y que aun hoy perduren.

La tercera es la que explica normas como las Poor laws o instituciones como los workhouse $e^{17}$, donde a la inclinación asistencial se superpone una pauta disci-

16 Moulier-Boutang (2006: 36 y 37) habla de una permanente tentación autoritaria del mercado laboral, orientado a embridar, esto es a refrenar y a sujetar la libertad y movilidad del trabajador.

17 Este «utilitarismo penal» también tuvo eco en el resto de los estados modernos (y contemporáneos). Así, en la Corona de Castilla durante los siglos XVI y xvir la pena más impuesta fue la de galeras, el 89 \% del total de penas consistía en estos trabajos forzados en galeras (Oliver, 2007: 20); la condena a galeras en teoría duraba 10 ańos, pero normalmente morían antes los galeotes por efecto del trabajo. 
plinaria y coercitiva con respecto a las clases menesterosas ${ }^{18}$, pues la ociosidad es la madre de todos los vicios (para los pobres, claro) ${ }^{19}$. Este objetivo disciplinario es el que parece estar presente en instituciones como el Verdingkinder suizo, indentured child laborers, por el que se obligaba a menores de edad a trabajar para personas ajenas, normalmente en granjas, sin contraprestación, siendo extraídos de sus familias por razones económicas o morales ${ }^{20}$.

La cuarta corre paralela a una compresión del mundo que opone a un nosotros inclusivo, una población diferenciada y cosificada, dentro o fuera de las fronteras ${ }^{21}$. Y fundamenta tanto el sistema kafala como la propia trata de seres humanos.

Por supuesto, que estas motivaciones se superponen y no actúan de forma asilada. Así en la werdingenkinder suiza latía también, más allá de la finalidad disciplinaria, la de ofertar mano barata en las granjas no mecanizadas, de ahí que la institución desaparecía entre los años 60 y 70, cuando estas se mecanizaron (BBC, 2014) ${ }^{22}$. Un ejemplo de como se superponen estas finalidades lo encontramos en el proyecto asistencial de naturaleza erasmista que comienza con el estado moderno, que se centra en la naturaleza disciplinaria del trabajo y busca asegurar mano de obra abundante y barata (Carasa, 2000: 39).

El trabajo esclavo y el trabajo sometido a sujeción se fundamenta en «la concepción del otro y del "diferente» no como persona titular de derechos y de dignidad, sino como verdadera cosa (res) objeto de extrañamiento, de neutralización y de sobreexplotación» (García, 2014: 2076). Este proceso de cosificación conlleva la anulación del concepto mismo de persona y de la dignidad inherente a esa condición ${ }^{23}$.

18 Una crítica al sistema de las workhouse y de las leyes de pobres puede verse en las obras de Charles Dickens, por ejemplo en Oliver Twist, donde se plasma el hambre y la explotación que sufren los huérfanos acogidos a este sistema; ya desde el primer capítulo Oliver comienza a trabajar con 10 ańos en la elaboración de estopa, y como castigo a su petición de más comida es cedido a cambio de 5 libras a un enterrador para que trabaje en ese negocio.

19 Así lo presenta Vives en su Tratado del Socorro de los pobres en 1525: «A ningún pobre que por su edad y salud pueda trabajar se le ha de permitir estar ocioso (...)no sea que por el ocio aprendan la desidia (Vives, 2000: 169 y 176).

20 Esta institución estuvo vigente en Suiza de 1850 hasta 1970 y si las padres se oponían a esa cesión podrían ser encarcelados (BBC News, 29.10.2014).

21 Moulier Boutang (2006: 229) expresa esta idea afirmando que «el mercado de trabajo libre no es más que una elemento de un conjunto mayor en cuyo seno se hallan consistentes segmentos de trabajo dependiente no libre». Algo antes, este autor plantea que en un mercado jerarquizado el trabajo exógeno se transforma en una división del trabajo etnizada (Moulier Boutang, 2006: 112).

22 En el mismo sentido, como comenta Mendiola (2007: 50-56) toda la explotación laboral de los presos en el franquismo se justificaba, además de en un evidente interés económico, en la corrección del prisionero mediante la adquisición del hábito de la profunda disciplina (art. 2 del Reglamento de los Batallones de trabajo).

23 Kant quizás sea el autor más conocido que plantea que la persona no puede ser considerada un simple medio, no se le debe convertir en una mera cosa, pues es un fin en sí misma: $N o$ te conviertas en un simple medio para los demás, sino sé para ellos a la vez un fin» (Kant, 2005: 47). En esta misma obra se reitera la idea de la humanidad, lo común a todos los hombres, como dignidad (Kant, 2005: 335). 
La globalización económica al desregularizar los mercado mundiales ha aumentado la vulnerabilidad de los más débiles y ha acrecentado las relaciones laborales sin libertad y sin derechos ${ }^{24}$ (Baylos, 2015 y Bales, 2000.a: 474). En el contexto de desplazamientos migratorios de refugiados que huyen de guerras y conflictos abundan las posibilidades de explotación de estas personas sin papeles, sin derechos, desplazados y desamparados ${ }^{25}$. Refiriéndose a la trata de seres humanos, Rubio y Pérez (2016) subrayan que uno de los problemas fundamentales sobre la misma es el «...choque frontal existente entre el actual modelo mundializado de libre circulación de mercancias y capitales frente a las diferentes restricciones a la libre circulación de personas...». Esta contradicción conlleva tanto el incremento de ese tráfico ilícito como la posibilidad de esclavizar a las víctimas de la trata.

\section{Diferencias entre la esclavitud tradicional y la actual}

A pesar de la persistencia del fenómeno del trabajo esclavo, se constatan diferencias entre la esclavitud contemporánea y la pasada. En la antigüedad, la ley propugnaba la posesión de una persona por otra ${ }^{26}$, pero en la nueva esclavitud se produce normalmente a despecho de la ley escrita; su existencia se convierte en un acto criminal y no se fundamenta en la propiedad absoluta sino en el control (Bales, 2000b: 189-190). Nadie acudirá hoy a los tribunales a que se proteja su derecho de propiedad sobre otra persona. Pero el dominio sobre otra persona, someterla a la condición de mero objeto, se puede conseguir con otros medios coactivos.

En este sentido, el propio Bales en otra fuente de ese mismo año (Bales, 2000a: 462) define la esclavitud contemporánea como "the complete control of a person for economice exploitation by violence or the threat of violence». Esta misma diferencia se constataba en el informe sobre "La Abolición de la Esclavitud y sus Formas contemporáneas» donde expresamente se advertía que «.. el criterio de propiedad puede eclipsar algunas de las otras caracteristicas de la esclavitud que tienen que ver con el control absoluto a que es sometida la victima de la esclavitud por otro ser humano,...", si bien se consideraba en este informe que las nuevas formas contemporáneas de esclavitud podían subsumirse en la de-

24 Es de reseñar que en el contexto de globalidad económica actual aunque los talleres esclavos se encuentren en Brasil los beneficiarios pueden ser empresas como Inditex (El Confidencial, 19.08.2011). Lo mismo ocurre con el trabajo por deudas en la India, donde las beneficiarias pueden ser empresas como el Corte Ingles, Inditex, H\&M,... (El Confidencial 23.03.2012).

25 Estos días ha surgido la denuncia de la explotación de niños sirios refugiados en Turquía cuyos beneficiarios son empresas textiles europeas como Zara o Mango ( $B B C 24.10 .2016$ ).

26 Hay autores como Casadei (2009: 171) que distinguen en la esclavitud tradicional una tendencia occidental centrada en la propiedad y una esclavitud oriental basada en el rango y el estatus, pero existiendo manifestaciones de ambas en las dos zonas. 
finición de esclavitud del Convenio 1926 (Weissbrodt y Anti-Slavery International, 2002: 7). Eduardo Rojo (2014) apunta esta misma separación de las nuevas formas de esclavitud sobre el concepto de la esclavitud de los tratados internacionales, si bien a su juicio estas nuevas formas de esclavitud tiene muchos puntos de conexión con el trabajo forzoso.

En la esclavitud contemporánea de facto el trabajador es sometido a condición de servidumbre mediante la violencia, la amenaza, el engaño,...pero se ejercen sobre él poderes análogos a los atribuidos al derecho de propiedad (García, 2014: 2073). Sin embargo, aunque por medio de estos procedimientos se pueda obtener un dominio sobre el trabajador equivalente al derivado al derecho de propiedad, puede ocurrir que los jueces no aprecien que se ejerzan atribuciones inherentes al derecho de propiedad. Aunque el resultado sea el mismo, el instrumento varía, de ahí que pueda ser recomendable una matización normativa al respecto.

Como constatan diversos autores, la nueva esclavitud actual se expande y se refuerza a medida que el orden social se disgrega (Casadei, 2009: 177, Bales, 2016:16). De ahí que Libia, donde la estructura del Estado se ha difuminado y pululan diversas facciones armadas, se haya convertido en una lugar donde prolifera impunemente la nueva esclavitud; cerca del 70\% de los refugiados que intentan cruzar el Mediterráneo es sometido a esclavitud, trata de seres humanos, secuestro, encarcelamiento... (The Independent, 18.10.2016).

Por su parte la ONG Antislavery caracteriza a alguien como sometido a esclavitud si es forzado a trabajar por medio de amenazas físicas o psíquicas, se encuentra bajo el control o en propiedad de un empleador, sufriendo un trato deshumanizado como una mercancía, es objeto de comercio y está sometido a limitaciones en su libertad de movimiento.

Como formas de la esclavitud moderna se señalan la prendaria, la servidumbre por endeudamiento y la contractual (Bales, 2000b: 26-2727). La primera es la mas cercana a la antigua esclavitud y se mantiene entre descendientes de esclavos, por la fuerza de la cultura y la tradición en zonas como Mauritania o Niger. La segunda es habitual tanto en países asiáticos como Pakistán o Bangladesh, pero también en países occidentales. La tercera es la que utiliza el ropaje de un contrato para amparar un relación de sujeción, propia de los talleres clandestinos de Brasil y de las relaciones laborales con extranjeros en ciertos países árabes.

La ONG Antislavery enumera diversos situaciones que considera esclavitud: el trabajo forzoso y la servidumbre por deudas, la trata de seres humanos, la es-

27 En inglés las presenta como Chattel Slavery, Debt Bondage and Contract Slavery (Bales, 2000a: 464). Este autor no excluye, ademas de las 3 citadas, la existencia de otros tipos de esclavitud vinculadas al poder político, como la "war slavery» con papel relevante en Birmania y otros países en permanente conflicto (Bales, 2000a: 464). 
clavitud basada en la ascendencia, la explotación de los trabajadores migrantes en condiciones equivalentes a la esclavitud, las peores formas de trabajo infantil y la esclavitud en las cadenas de suministro ${ }^{28}$.

Mi apreciación personal es que subsisten fórmulas cercanas a las tradicionales, especialmente en los países en desarrollo, con persistencia de facto de la esclavitud étnica, del trabajo forzado y de la servidumbre por deudas, todas ellas fundamentadas en situaciones de gleba, estamentales o de diferenciación étnica ${ }^{29}$. Pero también están cuajando otras formas diferentes como la neo-servidumbre ${ }^{30}$, el trabajo clandestino o el vinculado a conductas ilícitas (prostitución coactiva o la mendicidad obligada), posibles tanto en países en desarrollo como en los más desarrollados ${ }^{31}$. Por supuesto, que formalmente tanto en el trabajo clandestino como en las actividades delictivas (incluida la prostitución coactiva) se articulan como un trabajo por deuda, real o ficticia ${ }^{32}$, en definitiva, generando una servidumbre por deudas de nuevo cuño.

Dentro del trabajo asalariado de nuestra época la situación de los trabajadores extranjeros en ciertos Estados árabes del Golfo ${ }^{33}$, dentro del sistema kafala ${ }^{34}$, choca con nuestra compresión de la relación contractual laboral aceptable, pues están sometidos a ciertas constricciones que limitan severamente su libertad (aumentando desproporcionadamente los poderes del empresario sponsor) ${ }^{35}$. Estos nuevos metecos, que son inmensamente mayoritarios en la producción de esos países (superior al $90 \%$ de la población activa en Qatar, por ejemplo) no pue-

28 A estas formas de trabajo ańaden el matrimonio forzado y precoz, situación asimilada a la esclavitud, pero que no requiere en principio prestación laboral.

29 En el informe de OIT se constata que existen formas tradicionales de trabajo forzoso cercanas a al servidumbre en Asia Meridional, servidumbre por deudas entre indigenas en America latina y prácticas cercanas a la esclavitud en Africa.

30 La Recomendación 1523 de 2001 de 26 de junio, de la Asamblea Parlamentaria del Consejo de Europa introduce en el sistema jurídico europeo, aunque sin efectos normativos vinculantes para los Estado miembros, esa nueva forma de esclavitud, servidumbre doméstica.

31 Ya hemos dejado constancia de que, más allá de dónde se encuentren los talleres clandestinos, los beneficiarios últimos pueden ser multinacionales globalizadas.

32 De hecho en la Circular 5/2011 del Fiscal general del Estado sobre criterios para la unidad de actuación especializada del Ministerio Fiscal en materia de extranjería e inmigración se afirma que la trata de seres de humanos en Espańa esta vinculada a esta servidumbre por deudas, "es decir cuando el afectado se somete a la situación de dominación como único medio de satisfacer las deudas con el tratante».

33 El más aireado en las campañas de las ONGS (Amnistía internacional, Migrant Rights,..) es el de Qatar, al ser este pequeño país con monarquía absoluta el responsable del Mundial de Fútbol en 2022. Pero también se utiliza en Arabia Saudi y en otros países del entorno, si bien algunos de ellos ya han efectuado modificaciones del sistema, como Baréin. En el caso de Qatar se anuncian reformas del sistema presionados por la FIFA, pero se adivinan más cosméticas que efectivas (The Guardián, 10.10.2016).

34 En el derecho musulmán la kafala es una forma de adopción sin cambio de filiación del menor.

35 Se estima que existen más de 1.500 .000 trabajadores, la mayoría asiáticos (hindúes, pakistaníes, nepalíes,...) en Qatar bajo este sistema, mientras que las personas con nacionalidad catarí no llegan al $15 \%$ de la población, unos 300.000 personas. 
den abandonar el país, ni dejar su empleo, ni encontrar nuevo empleo salvo que el anterior empresario, el kafeel, lo autorice ${ }^{36}$. Como se ve, la libertad de trabajo queda severamente constreñida, posibilitando con facilidad situaciones de mayor abuso ${ }^{37}$; retención de pasaportes ${ }^{38}$, impago de salarios, violencias ${ }^{39} \ldots$ Con la quiebra de la empresa sponsor la situación de los trabajadores se vuelve terriblemente delicada, pues las empresas no les pueden autorizar a salir del país, ni a dejar el empleo, ni a conseguir uno nuevo,... mientras que los trabajadores ni tienen dinero para sobrevivir, ni para salir del país (El País, 12.09.2016).

\section{Concepto de esclavitud, trabajo forzoso, diferencias y matices entre esclavitud, trabajo forzoso y servidumbre}

\subsection{Concepto de esclavitud y de otras formas de trabajo coactivas en las normas internacionales}

En este apartado intentaremos presentar los conceptos de esclavitud, de servidumbre y de los trabajos forzados a la luz de las normas internacionales, y al mismo tiempo esto nos propicia que podamos presentar esas mismas fuentes. Podríamos traer a colación la configuración de la trata de seres humanos ${ }^{40}$, pero preferimos centramos en la situación y actividad del esclavo, no en el comercio previo. Nos basta señalar que esta intervención cuenta con una importante tradición internacional que se remonta al Convenio para la represión de la trata de personas y de la explotación de la prostitución ajena, adoptado por la ONU el 2 de diciembre de 1949. Posteriormente en el año 2000 se adoptó en Palermo el Protocolo de las Naciones Unidas para Prevenir, Reprimir y Sancionar la Trata de Personas, Especialmente Mujeres y Niños ${ }^{41}$.

36 Como precisa la ONG Migrant Rights es una forma de control, donde los gobiernos delegan el poder y el control sobre los trabajadores inmigrantes en ciudadanos y empresas privadas (https:// www.migrant-rights.org/2015/03/understanding-kafala-an-archaic-law-at-cross-purposes-with-modern-development/).

37 Como dice Kan (The Guardian, 26.02.2014) los trabajadores están sometidos al chantaje del sponsor, pues de denunciar las situaciones este puede ordenar su deportación reteniendo los salarios impagados.

38 Según relata la ONG Migrants rights el $90 \%$ de los trabajadores de bajos ingresos sometidos a kafala en Qatar a los que se entrevistó tenía confiscado el pasaporte.

39 La habitualidad de este tipo de abusos en contra de la norma catarí se denuncia en el informe de Amnistía Internacional (2016: 355).

40 La palabra trata tiene en castellano una compresión conectado con la esclavitud o el comercio de seres humanos (cf. DRALE).

41 En este protocolo se define La «trata de personas» como "...el reclutamiento, transporte, traslado, acogida o recepción de personas, bajo amenaza o por el uso de la fuerza u otra forma de coerción, secuestro, fraude, engaño, abuso de poder o una posición de vulnerabilidad, o recibir pago o beneficios para conseguir que una persona tenga bajo su control a otra persona, para el propósito de explotación. La explo- 
Existe una compresión más o menos inmediata de la esclavitud, como el dominio de una persona por otra. De una forma gráfica Aristóteles presentaba al esclavo como una propiedad viva ${ }^{42}$.

En la actualidad en los tratados internacionales se define de manera más exacta como "el estado o condición de un individuo sobre el cual se ejercitan los atributos del derecho de propiedad o algunos de ellos», según el art. 1 de la Convención de 25 de septiembre de 1926. Este convenio, efectuado en el seno de la Sociedad de Naciones, es el marco normativo internacional sobre la esclavitud y entro en vigor en $1927^{43}$. En este sentido, la esclavitud sería la negación de la noción de persona como un fin en sí mismo y la capacidad de autodeterminarse. La coletilla "o algunos de ellos» (de los atributos del derecho de propiedad) si bien crea una cierta indefinición, pues no se especifica cuál de ellos es definitivo, se aduce que su inclusión posibilita una definición más amplia e integral no limitada a las formas de esclavitud vinculadas a la trata transoceánica (Weissbrodt y Anti-Slavery International, 2002: 7).

En el siguiente párrafo del art. 1 del Convenio de 1926 se define la trata como "todo acto de captura, adquisición o cesión de un individuo para venderlo o cambiarlo; todo acto de cesión por venta o cambio de un esclavo, adquirido para venderlo o cambiarlo, y en general todo acto de comercio o de transporte de esclavos» (art. 1, párr. 2).

En 1953 (9 de septiembre) se adoptó un protocolo, ya dentro de las $\mathrm{Na}$ ciones Unidas, que modificaba la Convención de 1926 (Convención suplementaria sobre la abolición de la esclavitud, la trata de esclavos y las instituciones y prácticas análogas a la esclavitud) ${ }^{44}$, en el que se asimilaban a la esclavitud diversas formas de servidumbre: servidumbre por deudas ${ }^{45}$, servidumbre de gleba ${ }^{46}$, servidumbres de menores ${ }^{47}$ y de mujeres ${ }^{48}$. A pesar de que se

tación puede incluir, como mínimo, la explotación de la prostitución de otros u otra forma de explotación sexual, trabajo forzado o servicios, esclavitud, o prácticas similares a la esclavitud, servidumbre, o remoción de órganos...». Esta definición es el origen de otras posteriores, incluso de las que se contemplan en el Código Penal español.

42 Política, libro 1, capítulo II.

43 Ratificado por España en 1927 y publicado en la Gaceta de Madrid de 22.12.1927.

44 Ratificado por España en 1967 y publicado en el BOE de 29.12.1967.

45 Definida como "el estado o la condición que resulta del hecho de que un deudor se haya comprometido a prestar sus servicios personales, o los de alguien sobre quien ejerce autoridad, como garantía de una deuda...".

46 Definida como "la condición de la persona que está obligada por la ley, por la costumbre o por un acuerdo a vivir y a trabajar sobre una tierra que pertenece a otra persona y a prestar a ésta, mediante remuneración o gratuitamente, determinados ser-vicios, sin libertad para cambiar su condición».

47 Que se presenta como "Toda instituciónn o práctica en virtud de la cual un niño o un joven menor de 18 años es entregado por sus padres, o por uno de ellos, o por su tutor, a otra persona, mediante remuneración o sin ella, con el propósito de que se explote la persona o el trabajo del niño o del joven".

48 Centradas en el matrimonio forzoso o cesión de la mujer a terceros por parte de sus parientes. 
identifican esos tipos, no hay en esta Convención, ni en ningún otra norma internacional, una definición de lo que se entiende por servidumbre ${ }^{49}$.

Desde otro ángulo, la OIT ha intervenido en este ámbito en torno al trabajo forzoso. El Convenio 29 de la OIT sobre el trabajo forzoso ${ }^{50}$ (1930) lo define en el art. 2.1 como "todo trabajo o servicio exigido a un individuo bajo la amenaza de una pena cualquiera y para el cual dicho individuo no se ofrece voluntariamente» ${ }^{51}$. En el párrafo siguiente, 2.2 , se enumera una larga serie de excepciones a esta prohibición del trabajo forzado: servicio militar, obligaciones cívicas normales, trabajo de presos condenados ${ }^{52}$, fuerza mayor y trabajo menores comunales. Como se ve, la intervención de la OIT se centra en la falta de libertad de ese trabajo, cuya aceptación se consigue mediante amenazas y no se centra en la propiedad. Pero el Convenio plantea la supresión del trabajo forzado lo mas pronta posible, lo que deja la concreción de la prohibición en el aire.

De ahí que en 1957 se adoptara otro Convenio relativo a la Abolición del trabajo forzoso, 105 de la OIT $^{53}$, que obligaba a los Estados firmantes a prohibir el trabajo forzoso de carácter discriminatorio, como represalia por actividades políticas, sindicales, huelga ${ }^{54}, \ldots$

Posteriormente se ha adoptado un Protocolo en 2014, relativo al Convenio sobre el trabajo forzoso, 1930, encaminado a prevenir y eliminar su utilización, a proporcionar a las víctimas protección y el acceso a acciones jurídicas y de reparación apropiadas y eficaces, tales como una indemnización, y a sancionar a los autores del trabajo forzoso u obligatorio (art. 1) ${ }^{55}$. Es un instrumento más ambicioso y adecuado a las nuevas formas de esclavitud y trabajo coactivo vinculadas a la trata de seres humanos, que incluye medidas sobre los actores económicos públicos y privados para que actúen con la debida diligencia a fin de prevenir el trabajo forzoso u obligatorio y de responder a los ries-

49 Villacampa (2011), que resalta esta dato, define la servidumbre «como la prestación no libre de cualquier tipo de servicio, impuesto mediante medios que coarten la libertad de acción de la víctima».

50 Ratificado por España el 29 de agosto de 1932.

51 Este Convenio se ha ratificado por 170 Estados. Existe una recomendación de ese mismo año, número 35 de la OIT, sobre la imposición indirecta del trabajo.

52 Merece destacarse que el propio texto del Convenio elimina la posibilidad de ceder esos trabajos a empresas o particulares privados, extremo que no se cumplía en la Espańa franquicia ni el convict lease de los estados sureńos de EEUU.

53 Ratificado por Espańa el 6 de noviembre de1967.

54 Desde el punto de vista laboral es remarcaba que no se puede hacer uso del trabajo forzoso como medida disciplinaria, punitiva por huelga o discriminatoria ( art. 1c, d y e del Convenio 105 OIT).

55 Existe un movimiento, 50 FOR FREEDOW (http://50forfreedom.org/es/ ) que aboga porque este protocolo se convierta en Convenio de la OIT, mediante la firma de 50 Estados miembros. De momento son 8 los Estados que la han ratificado: Níger, Noruega, el Reino Unido. Mauritania, Mali, Francia, la República Checa y Panamá. 
gos que conlleva (art. 2.e) e, incluso, incita a las Estados a que realicen acciones para abordar las causas generadoras y los factores que aumentan el riesgo de trabajo forzoso u obligatorio (art. 2 f). También se ha adoptado una Recomendación, 203, sobre el trabajo forzoso (medidas complementarias) en 2014 que se encamina a prestar orientación práctica sin carácter voluntario sobre los temas del protocolo ${ }^{56}$.

En diferentes y transcendentes instrumentos de reconocimiento internacional y derechos humanos, como en la Declaración Universal de los Derechos del Hombre 1948, se recoge la prohibición de la esclavitud y de la servidumbre; art. 4, "nadie estará sometido a esclavitud y a servidumbre; la esclavitud y la trata de esclavos están prohibidas en todas sus formas». También en el Pacto Internacional de Derechos Civiles y Políticos (1966) se recoge esta prohibición de la esclavitud y de los trabajos forzados (art. 8).

En el ámbito europeo, de igual manera, se recoge en el Convenio Europeo de Derechos Humanos, si bien en el artículo 5 de esta norma se incluye además de la prohibición de la esclavitud, de la servidumbre y de la trata, la prohibición de ser constreñido a realizar trabajos forzosos. Y simétricamente también en el art. 5 de la Carta Europea de los derechos fundamentales de la Unión Europea se recoge esta prohibición de la esclavitud y la servidumbre y la imposibilidad de obligar a efectuar trabajos forzados ${ }^{57}$.

Es interesante resaltar la jurisprudencia del Tribunal Europeo de Derechos Humanos, al enjuiciar el cumplimiento de la Carta Europea por parte de los Estados, pues en diversas resoluciones ha condenado a diversos Estados por falta de protección en supuestos de servidumbre domestica; STEDH de 26 julio 2005, Caso Saladin contra Francia, STEDH de 11 octubre 2012, caso C.N. contra Francia, STDH de 13 de noviembre de 2012, caso C.N. contra Reino Unido...Todas ellas abordan supuestos de mujeres africanas, las dos primeras menores de edad, que han trabajado de forma coactiva en condiciones incompatibles con la dignidad (retención de documentación, aislamiento, no remuneración, etc. $)^{58}$. Existen otras resoluciones que abordan situaciones conectadas con la esclavitud, la trata de seres humanos y los trabajos coactivos. Así en la STEDH de 7 de enero de 2010, Caso Rantsev contra Chipre y Rusia, se con-

56 Existen otros convenios como el Convenio 182 sobre las peores formas de trabajo infantil, 1999 (núm. 182), donde se recoge la prohibición de "todas las formas de esclavitud o las prácticas análogas a la esclavitud, como la venta y la trata de niños, la servidumbre por deudas y la condición de siervo, y el trabajo forzoso $u$ obligatorio, incluido el reclutamiento forzoso $u$ obligatorio de niños para utilizarlos en conflictos armados». En el propio texto normativo se presenta el trabajo forzoso como una forma de esclavitud.

57 Sobre el contenido de este artículo puede verse López (2014).

58 En los 3 casos se pondera que en ambos Estados, Francia y Reino Unido, carece de tipificación como delito la esclavitud y servidumbre, extremo que también concurre en Espańa. 
dena a ambos Estados por no haber protegido la vida de un inmigrante ilegal. Más recientemente, en la STEDH de 21 enero de 2016, Caso L.E. contra Grecia, se condena al Estado en un supuesto de trata de seres humanos y de prostitución coactiva ${ }^{59}$.

Constatamos, por último, que en los textos doctrinales y de las organizaciones internacionales se habla mucho de nuevas formas de esclavitud moderna o contemporánea, pero eso no se ha traducido en una intervención normativa ${ }^{60}$.

\subsection{Diferencias y matices entre esclavitud, trabajo forzoso y servidumbre}

La OIT suele mantener que la esclavitud es una especie de trabajo forzado ${ }^{61}$; podríamos entender que el trabajo forzado es la perspectiva laboral de la esclavitud, si bien, no todo trabajo forzado es trabajo esclavo, ni necesariamente toda esclavitud conlleva una prestación de servicios, pues dentro del concepto de esclavitud entra la utilización del esclavo como mero objeto sexual personal, por ejemplo.

Ahora bien, nosotros creemos que desde un punto vista teórico puede diferenciarse la esclavitud de los trabajos forzados. En primer lugar, porque la esclavitud no admite exclusiones, mientras que los trabajos forzados sí (art. 2 Convenio OIT 29). De hecho, ya en la Convención de 1926, en el art. 5, se exoneran de la prohibición de la esclavitud los trabajos forzados que posean utilidad pública. Además, los trabajos forzados centran la compulsión en la actividad laboral, no en otros aspectos de la personalidad, mientras que la sujeción de la esclavitud se extiende por todos los ámbitos de la persona. Por ultimo, el trabajo forzoso se centra en la falta de libertad en la aceptación del trabajo, en la imposibilidad de ruptura por parte del trabajador, pero el trabajo esclavo conlleva además un proceso de cosificación en el trabajo. De ahí que en el art. 5 del convenio de 1926 se comprometan los Estados firmantes a «tomar las medidas pertinentes para evitar que el trabajo forzoso u obligatorio lleve consigo condiciones análogas a la esclavitud». En definitiva, desde el punto de vista laboral la esclavitud y la servidumbre son prestaciones de servicios con vínculos de sujeción personal, extremo que no concurre en otro tipo de trabajos forzados de forma necesaria.

59 Existe un caso similar con una ciudadana de idéntica nacionalidad nigeriana y situación, que afecta a Espańa, pendiente de resolución.

60 En la campaña de 50 for Freedom que impulsa la ratificación del Protocolo de 214 se habla de esclavitud moderna, expresión que, sin embargo, el Protocolo no utiliza. De manera similar en la norma del Reino Unido aparece esa denominación, Modern Slavery Act, pero la definición no varía.

61 Véase esta afirmación en http://www.ilo.org/global/topics/forced-labour/lang--es/index.htm. Paralelamente en algún texto normativo (Convenio 182 OIT) se efectúa la equiparación inversa que el trabajo forzado es una forma de esclavitud. 
Se puede añadir que la expresión "trabajos forzados» conecta con la acepción de pena impuesta a los reos o presos por el Estado como medida punitiva (cf. DRALE), sin bien en los textos normativos se incluyen también situaciones donde la compulsión es meramente privada.

Dicho esto, en la práctica las cosas son más obscuras. Así, en el ejemplo extremo de trabajo forzado en la Europa del siglo $\mathrm{xx}^{62}$, la Alemania nazi, las situaciones de compulsión contra los «enemigos del estado» (por motivos políticos, raciales, sociales,...) se acercaban más a la esclavitud, con negación de los derechos incluso sobre el control sobre el propio cuerpo (experimentos de tipo médico) o el exterminio sistemático ${ }^{63}$. En este sentido, Rodríguez-Piñero (2011a: 310) afirma que, a pesar de las diferencias jurídicas entre la esclavitud, la servidumbre de mercado y los trabajos forzados impuestos por las autoridades, existen tantas similitudes entre ellas que es difícil diferenciarlas nítidamente.

La delimitación entre servidumbre y la esclavitud es de grado en los derechos constreñidos, se entiende que en la situación de servidumbre se mantiene la personalidad del siervo y algunos de sus derechos personales. Pero a la luz de la Convención de 1926 y el protocolo complementario de 1953, esas situaciones de servidumbre se consideran prácticas análogas a la esclavitud, con lo que la diferenciación no conlleva mayor relevancia en ese marco jurídico. En otros ámbitos, se puede mantener esa diferenciación. Así, por ejemplo, en el ámbito del Convenio Europeo, la STEDH 26 de julio de 2005, entendió que no concurría un supuesto de esclavitud pues no se constatan que se hubieran ejercido derechos de propiedad sobre la trabajadora; se acudió al supuesto de servidumbre de menor, entregado a terceros para efectuar servicios, para entender que era una servidumbre doméstica.

Por último, se puede constar una cierta insuficiencia de las formas reguladas en las normas internacionales (en especial, de la esclavitud basada en la propiedad) y las nuevas formas de esclavitud, pues en estas aunque se acercan a las condiciones materiales de aquellas, se basan en medios coactivos violentos y no en fórmulas jurídicas aceptadas socialmente.

62 El volumen de trabajo forzado al final de la II guerra mundial en la Alemania Nazi fue muy elevado, alrededor de 7,7 millones de trabajadores extranjeros y prisioneros de guerra trabajaban en la industria y la agricultura alemana (Sanz, 2007: 32). Además, unos 600.000 prisioneros de campos de concentración prestaban servicios para empresas privadas alemanas (Daimeler Benz, Krupp, Siemens,...). A modo de ejemplo de la importancia que adquiere este sistema en la economía nazi, en empresas como Volkswagenwerk el número de los trabajadores forzados extranjeros y los prisioneros de guerra era superior al de los trabajadores alemanes desde 1942 (Sanz, 2007: 39).

63 Wachsmann (2015: 464) afirma que "Si se usa el vocablo (esclavo) en un sentido lato, para descubrir un sistema de dominación basado en la fuerza y el terror, encaminado a obtener beneficios por medio de la subyugación de los parias sociales habrá que reconocer que expresa con fidelidad la suerte de muchos de cuantos estuvieron recluidos en los KL durante la IIGM, y en particular en los estados últimos de esta». 


\section{Esclavitud y trabajo esclavo en el derecho interno}

No existen demasiadas alusiones directas a la prohibición de la esclavitud o los trabajos coactivos en el derecho interno; en la CE la única mención directa es la contenida en el art. $25 \mathrm{CE}$, las penas privativas y las medias de seguridad... no podrán consistir en trabajos forzados. De todas formas, debe recalcarse que se trata de una prohibición no circunscrita a los españoles, y que restringe la posibilidad de los trabajos forzados admitida en el Convenio 29 de la OIT e incluso planteando en la Convención de 1926 sobre la esclavitud. A nuestro entender, esta mención supone asumir indirectamente la prohibición de los trabajos coactivos en general, pues expresamente se elimina incluso aquella opción admitida en estos tratados internacionales ${ }^{64}$.

Sí que existen afirmaciones positivas (como el derecho al trabajo art. 35 referido solo a los espańoles) o la prohibición del trato degradante del art. $15 \mathrm{CE}$, de los podrían deducirse la prohibición de los trabajos coactivos o bajo sujeción.

En cualquier caso, este silencio relativo tampoco plantea mayores problemas dado la interiorizacion de los diversos tratados internacionales, donde se recoge esa prohibición, ratificados por España.

Ahora bien, en el ámbito punitivo y laboral la ausencia de tipificación plantea ciertos problemas. Como puntualiza Cuesta $(2008$,$) "La ausencia de tipifica-$ ción expresa de la esclavitud en nuestro ordenamiento jurídico ayuda a enmascarar la esclavitud bajo la designación de explotación...." ${ }^{65}$. De hecho, en supuestos claros de trabajos coactivas, como la STS penal 995/2000, de 30 de junio, donde incluso se le hizo firmar un "contrato de esclavo ${ }^{66}$ " al inmigrante llamándole esclavo y sometiendo a trabajos sin remuneración, se tiene que recurrir al tipo que penaba los trabajos de explotación laboral, porque como señala el Tribunal la esclavitud y la servidumbre no están tipificados como delito ${ }^{67}$ (art. 499.1.bis del CP de 1973 en aquel momento). La falta de definición genera, además, cierta

64 La nulidad de los arrendamientos de servicios contemplada en el art. 1583 del CC también debe entenderse en el sentido de que no son admisibles aquellas relaciones de servicios donde no hay libertad de ruptura bilateral.

65 La autora señala también esa confusión entre documentos internacionales donde parece equipararse la esclavitud, los trabajos coactivos o sometidos a sujeción, y la sobre-explotación. Aunque el artículo es de 2008, la posterior recepción del tipo de trata no ha modificado sustancialmente la cosas, salvo en lo referente a la trata conectada con la prostitución coactiva.

66 Salas distingue entre contrato de esclavo y trabajo de esclavo (2014: 42) entendiendo que el primero concurre cuando se fuerza la voluntad de quien no quiere prestar los servicios y el segundo cuando se imponen condiciones carentes de toda lenidad, como ausencia de salario, pero la distinción no nos convence pues los trabajos esclavos son siempre forzados y la voluntad de la víctima es irrelevante, pues, de existir, se produce de manera viciada.

67 La sentencia del TS revocó la SAP Guadalajara 46/1998 de 15 julio que consideraba que al ser extranjero no tenía derecho al trabajo ni podía apreciarse el supuesto de explotación. 
confusión jurisprudencial entre la esclavitud y la explotación laboral, pues se da un uso retórico e impreciso de la esclavitud ${ }^{68}$. A nuestro juicio, el trabajo esclavo o coactivo es, además de un supuesto explotación laboral, un atentado a la dignidad y libertad de la persona ${ }^{69}$.

En el ámbito europeo, la European Union Agency for Fundamental Rights utiliza la expresión severe labour explotation para este tipo de situaciones, que define como explotaciones laborales penalmente sancionadas de acuerdo con la legislación de un Estado miembro (FRA, 2016: 3), pero tampoco deslinda la explotación laboral de las formas de trabajo coactivo ${ }^{70}$. En nuestro derecho hay formas de explotación severas, en cuanto penadas por la ley, que no son formas de trabajo coactivo.

La reforma de 2010, Ley Orgánica 5/2010, de 22 de junio, modificó el CP, deslindando el tipo de la trata de seres humanos de la inmigración ilícita. Si bien es cierto que entre las finalidades que dan pie a la trata se recoge la imposición de la esclavitud o el trabajo forzoso, lo cierto es que no se han producido demasiadas sentencias que apliquen el art. 177.1 bis CP con esa finalidad ${ }^{71}$; una excepción puede ser la SAP Sevilla 536/2015 de 20 octubre, donde se aplica el delito de trata de seres humanos en supuestos de servidumbre laboral ${ }^{72}$. Casi todas las existentes son sobre trata de seres humanos y prostitución coactiva ${ }^{73}$.

68 En algunos supuestos se utiliza la expresión esclavitud y en contextos similares se habla de explotación, sin más. Además, alguna resolución, como la SAP de Huelva 27/2005 de 7 noviembre, habla de semi-esclavitud, y los datos que aporta identifican más bien, una situación de sobre-explotación laboral.

69 También en la doctrina se suele traducir la trata con finalidad de esclavizar o imponer la servidumbre como trata para la explotación laboral (Villacampa, 2012, Rubio y Pérez, 2016), aunque los autores sean conscientes de la diferencia que existente entre la explotación laboral y los trabajos coactivos En el Código Penal no se usa la expresión explotación laboral que parece construida en paralelo a la referencia a la explotación sexual o a la delictiva, que sí están en la norma. Pero la explotación laboral no agota, a nuestro juicio, la realidad de los trabajos coactivos.

70 Analizando con cautela la Directiva 2011/36/UE, de 5 de abril se debe entender que si bien el objetivo de la trata es la explotación (art. 2.1), se mantiene la diferencia entre explotación del trabajo y la imposición de formas de trabajo coactivas, pues se presentan de forma diferenciada en el art. 2.3.

71 En el informe del Defensor del Pueblo se constata la inexistencia de delitos de trata con esa finalidad, pero se aduce que quizás es pronto (Defensor del Pueblo, 2012: 55). Sin embargo, en el propio informe se recogen diversas actuaciones policiales donde se investigan situaciones cercanas al tráfico de seres humanos con finalidad de imponer trabajos coactivos, 50 personas trabajando en un taller clandestino en Madrid, u 8 víctimas de trata retenidas en una finca agrícola (Defensor del pueblo, 2012: 67 y 72).

72 Y en la STS penal 164/2014 de 13 febrero se contempla un supuesto de trata de seres humanos con finalidad de obligarles a la mendicidad.

73 Sentencias del TS que aprecian trata de seres y prostitución coactiva pueden citarse las siguientes: SSTS penal 538/2016 de 17 junio, 449/2016 de 25 de mayo, 545/2015 de 28 septiembre, $827 / 2015$ de 15 diciembre, 191/2015 de 9 abril... Las 3 últimas abordan supuestos con prostitución de menores. En todas ellas se dan características que delimitan un trabajo coactivo o sometido a sujeción, violencia, amenazas, retención de documentación, engaño, detención y limitación de la movilidad. 
Algunas fuentes señalan que se puede acudir al art. 311.1 (o al art. 312.2 en su caso) del CP, Circular 5/ 2011 del Fiscal General del Estado ${ }^{74}$, pero esto genera un equiparación con conductas menos graves ${ }^{75}$, pues aquí estamos ante un cosificación extrema (Villacampa, 2012), de ahí, que señale la posibilidad de acudir al delito de trato degradante. Como señalan Boronat y Grima (2009) el art. $311 \mathrm{CP}$ presume la voluntad del trabajo, extremo que no concurre en los supuestos de trabajos coactivos, bajo esclavitud o servidumbre, en el art. $311 \mathrm{CP}$ se imponen ciertas condiciones de trabajo, no el trabajo mismo.

También se debe señalar que en el art. 607 bis párrafo 10 del CP se sanciona de 4 a 8 años de prisión a quien imponga la esclavitud a otra persona dentro del delito de lesa humanidad, que implica un ataque generalizado contra la sociedad civil o parte de ella. Pero este artículo incluye la única definición sobre la esclavitud existente en nuestro derecho interno: "Por esclavitud se entenderá la situación de la persona sobre la que otro ejerce, incluso de hecho, todos o algunos de los atributos del derecho de propiedad, como comprarla, venderla, prestarla o darla en trueque».

Aunque se da en un ámbito muy concreto, delito de lesa humanidad, la definición modula la recogida en las normas internacionales, pues admite como tal cuando se ejercen de hecho los atributos de la propiedad y enumera algunos ejemplos de esa atribución que coinciden con ciertas prácticas de la trata de seres humanos; supuestos como el contemplado en el asunto Saladin (que fue traspasada a otros usuarios como un mero objeto) o aquellas donde es objeto de venta el trabajador entrarían en ese concepto, como por ejemplo el contemplado en la SSTS 270/2016 de 5 abril (venta de dos menores para dedicarlas a la prostitución ${ }^{76}$. Sin duda, esa admisión de las situaciones de hecho (y no solo de la propiedad en sentido jurídico estricto) facilitaría la compresión como esclavitud de las formas contemporáneas de trabajo coactivo ${ }^{77}$.

\section{Reconceptualizacion del trabajo esclavo a efectos laborales}

Creemos que es necesario una reconceptualización del trabajo esclavo a efectos laborales y punitivos. Recapitulamos las razones que nos inducen a platear esa necesidad y que ya hemos ido aduciendo anteriormente a lo largo de este trabajo.

\footnotetext{
${ }^{74}$ Alguna sentencia del TS la aplica en caso de trata con finalidad de explotación sexual también: STS 270/2016 de 5 abril.

75 Sí que existen algunos supuestos donde se aplica, en situaciones que perfilan un trabajo coactivo, retención de pasaporte, impago de salarios,... como la STS penal 221/2005 de 24 febrero.

${ }_{76}$ Quizás la enumeración se fija en exceso en algunos aspectos concretos de la esclavitud y no en otros, como la retención, secuestro o privación de libertad.

77 Por último, se debe señalar que el art. 611.9 CP alude a la esclavitud sexual impuesta en un conflicto armado (este partido fue añadido por la LO 5/2010, de 22 de junio).
} 
1. El concepto normativo sobre la esclavitud se basa en la propiedad (art. 1. de la Convención de 1930). Eso puede generar, como en la STEDH 26 de julio de 2005 (asunto Saladin contra Francia), que un tribunal considere que no existe esclavitud porque, si bien hay sujeción, no se encuadra en una relación jurídica de propiedad de una persona por otra. En las nuevas situaciones la sujeción no se articula mediante la propiedad, sino a través de otros procedimientos, por lo que es oportuno reflejar eso en la definición jurídica. Es necesario un aggiornamento del concepto de esclavitud y del trabajo esclavo o en servidumbre, pues como afirma Miñarro (2014) "...la delimitación clásica,..., no engloba formas más sutiles y modernas de esclavitud».

2. Además, las referencias normativas sobre la esclavitud o la servidumbre no especifican la singularidad del trabajo sometido a sujeción, donde no solo se produce una privación de la libertad de ruptura de la relación como el trabajo forzoso en sentido formal, sino que es consustancial al trabajo esclavo, la cosificación de la visita y el trato degradante (Salas, 2014: 42).

3. Creemos que la falta de delimitación genera confusión entre el trabajo esclavo y la explotación laboral ${ }^{78}$, originando una compresión aligerada del problema y una menor represión de esas conductas ${ }^{79}$.

4. La esclavitud, el trabajo sometido a sujeción, es una conducta pluriofensiva, que daña diversos derechos de la víctima, empezado por la propia negación de la condición de persona. En la normativa española se ha integrado la represión de la trata, penando esa actividad, sin que en el caso de la esclavitud y de los trabajos coactivos se haya efectuado una tipificación complementaria ${ }^{80}$.

Las características que a nuestro juicio concurren en el trabajo esclavo o sometido sujeción son las siguientes ${ }^{81}$ :

1. Dominación y sujeción del trabajador esclavizado. Al no estar amarrada en el concepto jurídico de propiedad (abolida formalmente en todos los estados), esta sujeción se fundamenta en otras fuentes de coacción: vio-

78 La propia OIT resalta que los trabajos forzados son distintos de la explotación laboral o de trabajos por debajo de la norma (OIT, http://www.ilo.org/global/about-the-ilo/newsroom/news/ WCMS_182014/lang--es/index.htm).

79 Recuérdese que casi no hemos encontrado resoluciones que apliquen trata de seres humanos en conexión con los trabajos esclavos.

80 De ahí que autores como Villacampa (2012) admitan la conveniencia de una reforma para su tipificación penal.

81 Una caracterización interesante es la desarrollada por Milńarro (2014), de la que, sin embargo, nos apartamos en algunos aspectos. 
lencia física, engaño, amenazas, abuso de superioridad ${ }^{82}, \ldots$ Todos ellos son medios coactivos ${ }^{83}$, el trabajo esclavizado no es fruto de la voluntad, y cuando esta exista está viciada de raíz, de ahí que las normas consideren irrelevante el consentimiento dado bajo esos medios (art. 177 bis. 3 CP o art. 2.4 de la Directiva 2011/36/UE).

2. Limitación de la libertad del trabajador, centrada específicamente en la imposibilidad o dificultad extrema para romper esa sujeción. Esta falta de libertad a menudo se concreta en la retención física o en el enclaustramiento de la víctima ${ }^{84}$.

3. Vulneración de los estándares mínimos laborales e imposibilidad por parte del trabajador de modificar las condiciones de la prestación. Los trabajadores esclavizados padecen condiciones por debajo de los estándares laborales, pero además carecen de poder para modificar esa situación.

4. «Cosificación» del trabajador ${ }^{85}$, esto es la relación de sujeción conlleva un atentado contra la dignidad del trabajador, la negación de su condición de persona ${ }^{86}$.

Si se repara un poco todas estas características también estaban presentes en la esclavitud sostenida en los atributos de la propiedad, pero ahora nos centramos en las lesiones que genera en los diversos derechos del trabajador sometido a trabajo coactivo. De hecho, con una interpretación que entendiera que esos atributos de la propiedad son ejercidos de hecho (como en el art. 607.bis párrafo $10 \mathrm{CP}$ ) y sustentados en una coacción o violencia incluiremos también las nuevas formas de esclavitud.

En cualquier caso, estas características identifican a nuestro juicio la singularidad del trabajo esclavo o coactivo y la diferencian de la explotación laboral. En la esclavitud se ataca y lesiona el concepto mismo de persona, vulnerando su libertad y su dignidad. En la explotación se imponen las condiciones de trabajo lesivas, en el trabajo coactivo se coacciona y se impone el mismo trabajo.

82 Son los medios enumerados en el art. 177 bis1.1 CP. Es frecuente que las víctimas sean menores de edad extranjeras tanto en supuestos de servidumbre doméstica (STEDH 26 de julio de $2005, \ldots$ ) como en los de explotación sexual $(827 / 2015$ de 15 diciembre, STS Penal 545/2015 de 28 sep. 2015, STS Penal 191/2015 de 9 abr. 2015...).

83 A menudo se priva del pasaporte o de la documentación a la víctima: STEDH 26 de julio de 2005, STEDH de 13 noviembre 2012, STS Penal 545/2015 de 28 sep. 2015,...

${ }^{84}$ Este es el supuesto de la STEDH de 13 noviembre 2012 y del enjuiciado en STS penal $827 / 2015$ de 15 dic. 2015 o de la STS, penal, 1045/2003, de 18 de junio.

85 En ocasiones, incluso en supuestos vistos ante los tribunales españoles, se dan casos de venta de ser humano sometido a explotación sexual STS 270/2016 de 5 abril.

${ }^{86}$ Muchos pueden ser los ejemplos de cosificación, de conversión en pura mercancía, pero la venta de menores para ejercer la prostitución es un caso claro, STS 270/2016 de 5 abril. 
Por supuesto, que como en la esclavitud tradicional, las diferencias entre unas y otras situaciones de sujeción son variadas. Y, además, las restricciones de la libertad que padecen las víctimas no son idénticas, pero tienen en común la anulación o perturbación grave en su libertad. En ocasiones, como en caso Saladin u otros, las víctimas se liberan de por sí, pero eso no cuestiona su sujeción (recuérdese que incluso en la esclavitud colonial, existieron los cimarrones, comunidades libres de esclavos huidos).

Por otro lado, estamos ante una conducta pluri-ofensiva que lesiona la libertad, la dignidad y otros derechos fundamentales del trabajador esclavizado.

Sería interesante tipificar el delito de trabajos coactivos, forzosos o en esclavitud, diferenciado del art. $311 \mathrm{CP}$ (o 312) ${ }^{87}$. La escasez de resoluciones que aúnan la trata de seres de humanos con la finalidad de imponer este tipo de trabajos indica que hay una carencia legal en ese ámbito.

En el ámbito laboral debería buscarse una espacio que posibilitara la intervención sancionadora específica para aquellos asuntos que no culminaran en la vía penal y, en todo caso, complementara la intervención penal.

Hay una nueva tendencia normativa, todavía incipiente, que inicie en las obligaciones de las empresas de asegurar que no se han beneficiado del trabajo coactivo de manera directa o a través de su cadena de proveedores. La primera de estas normas fue la California Transparency in Supply Chains Act ${ }^{88}$ donde se articula la obligación de informar a las empresas que facturen más de 100 millones de dólares de informar de los esfuerzos que han realizado para erradicar la esclavitud y el trabajo forzado de sus cadenas de suministro. En el ámbito Europeo, en el Reino Unido se aprobó el año pasado la Modern Act Slavery que impone a partir de marzo de este año la obligación a las empresas de efectuar una declaración anual en la que se plasmen los esfuerzos que han realizado para asegurar que no se han beneficiado del trabajo esclavo y el tráfico de personas. Sin embargo, como precisa Mireia Ferré (2016), esta iniciativa es en gran medida papel mojado, pues ni la norma contiene un contenido mínimo, ni prevé sanción alguna en caso de incumplimiento.

Sin duda, una tendencia real y efectiva en este sentido sería altamente deseable, y trasladaría la presión a las empresas beneficiarias.

En cualquier caso, como advierte el Protocolo de 2014, se debe intervenir en las causas y, parece evidente que una parte de ellas nace en la contradicción

87 En otros países como Portugal, Rumania o Eslovenia la esclavitud está penada de manera específica.

88 Es de destacar que la norma comienza reconociendo que la esclavitud existe en todo los Estados incluido el Estado de California; Slavery and human trafficking exist in every country, including the United States, and the State of California. 
entre la eliminación de las barreras para los bienes y el capital y su mantenimiento e incremento para la movilidad laboral de las personas. La vulnerabilidad de los migrantes es un factor que propicia su sujeción y coacción como mano de obra esclava. A la vista de la actuación europea en las últimas crisis humanitarias nos quepa mucho que hacer en este sentido.

\section{Bibliografía}

Alonso Olea, Manuel (2001): Introducción al Derecho de trabajo, Civitas, Madrid (6.a ed., $1 .{ }^{\text {a de. }}$ 1962).

Alcázar, Joan Del (Dir.) (2003): Historia contemporánea de América, Universidad de Valencia, Valencia.

BALEs, Kevin (2000a): «Expendable people: Slavery in the age of globalization», Journal of International Affairs, 53(2), 461-484. Retrieved from http://search.proquest.com/doc view/220693705? accountid $=17248$.

BaLes, Kevin (2000b): La nueva esclavitud en la economía global, Siglo XXI, Madrid.

Bales, Kevin (2016): «Connecting Slavery and Environmental Destruction» in Walk free foundation (2016): The global Index of slavery, Australia.

Baylos, Antonio (2015): «Erradicar el trabajo forzoso», Blog según Antonio Baylos, http:// baylos.blogspot.com.es/2015/10/erradicar-el-trabajo-forzoso.html

Boronat Tormo, M. y Grima Lizandra, V. (2009): «La esclavitud y la servidumbre en el derecho espańol: a propósito de la STEDH de 26 de julio de 2005 ("Siliadin cl Francia»): un caso de trabajo doméstico servil» en Carbonell Mateu, J.C., González Cussac, J. L., Orts Berenguer, E. Cuerda Arnau, M. L. (Coord.s): Constitución, derechos fundamentales y sistema penal: (semblanzas y estudios con motivo del setenta aniversario del profesor Tomás Salvador Vives Antón), Tirant lo Blanch, Valencia, 257-286.

Bush, Michael L. (2000): Servitude in modern times, Polity Press, Boston.

Caras Soto, P. (2000): «Juan Luis Vives y la reforma social. Estudio preliminar» en Vives, Juan Luis (2000): Tratado del socorro de los pobres, Ministerio de trabajo y Asuntos Sociales, 2000 (edición semifascimil de la edición castellana de 1781), 15-103.

Casadei, Thomas (2009): «La «nueva» esclavitud», Anales de la Cátedra Francisco Suarez $43,167-194$.

Defensor del Pueblo (2012): La trata de seres humanos en España: víctimas invisibles, Defensor del pueblo, Madrid.

European Union Agency for Fundamental Rights (2015): Severe labour exploitation: workers moving within or into the European Union - States' obligations and victims' rights, Austria.

Fernández-Costales Muñiz, Javier (2002): „El contrato de esclavo. Concepto de extranjero y su integración social a través de los derechos y libertades fundamentales en el ordenamiento español y europeo», Revista española de Derecho del Trabajo num. 110/2002

FerRÉ, Mireia (2016): «Obligaciones de „compliance» para prevenir el trabajo forzoso en las empresas. La „Modern Slavery Act» del Reino Unido», Noticias Juridicas.

Garcia Schwarz, Rodrigo (2014): «Trabajo forzoso»" en Baylos Grau, A.; Florenco Thomé, C. y Garcia Schwarz, R. (Coords.) (2014): Diccionario Internacional de Derecho de Trabajo y de la Seguridad Social, Tirant lo Blanch, Valencia, 2069-2086. 
ILO (2012): Global estimate of forced labour Executive summary.

ILO (2014): Profits and Poverty: The Economics of Forced Labour, International Labour Office, Geneva.

Kant, I. (2005): La metafísica de las costumbres. Ed. Tecnos, Madrid, (1. a ed or 1797)

LENGELLÉ-TARDY, Maurice (2002): La esclavitud moderna, Bellaterra, Barcelona

López Rubia, Edurne (2014): «Prohibición de la esclavitud y del trabajo forzado» en AAVV (2014): La Carta de los Derechos Fundamental de la Unión Europea y su reflejo en el ordenamiento jurídico español, Aranzadi, 105-124.

Mendiola Gonzalo, Fernando (2007): «Marco legal y consecuencias socioeconómicas de los trabajos forzados bajo el franquismo» en Gastón Aguas, Jose Miguel y Mendiola Gonzalo, Fernando (Coord): Los trabajos forzados en la dictadura franquista: Bortxazko lanak diktadura frankistan, Instituto Gerónimo de Uztáriz - Memoriam Bideak, 46-62.

Miñarro Yanini, Margarita (2014): «Formas esclavas de trabajo y servicio del hogar familiar: delimitación conceptual, problemática específica y propuestas (1), Relaciones Laborales, n.o 10, Sección Doctrina, Octubre 2014, Ańo 30, pág. 71 y ss.

Montoya Melgar, Alfredo: Derecho del Trabajo, Tecnos, Madrid (32. ${ }^{\mathrm{a}}$ ed, $1 .^{\mathrm{a}}$ ed. 1976)

Moulier-Boutang, Yann (2006): De la esclavitud al trabajo asalariado. Economía histórica del trabajo asalariado. Akal, Madrid (1. ${ }^{\text {a }}$ ed 1998).

Oficina de las Naciones Unidas contra la Droga y el delito (2010): Trata de personas hacia Europa con fines de explotación sexual.

Oliver Olmo, Pedro (2007): «Historia y reinvención del utilitarismo punitivo» en Gastón Aguas, José Miguel y Mendiola Gonzalo, Fernando (Coord): Los trabajos forzados en la dictadura franquista: Bortxazko lanak diktadura frankistan, Instituto Gerónimo de Uztáriz - Memoriam Bideak, Iruña, 18-29.

Rodríguez Montañés, Teresa (2014): «Trata de seres humanos y explotación laboral», La Ley Penal, n. ${ }^{\circ}$ 109, Julio-Agosto 2014.

Rodríguez-Piñero Bravo-Ferrer, Miguel (2011a): El trabajo obligatorio o forzoso, en De la Villa Gil, Luis Enrique (2011): El trabajo, Editorial Universitaria Ramón Areces, Madrid, 305-331

Rodríguez-Piñero y Bravo-Ferrer, Miguel (2011b): «La libertad de trabajo y la interdicción del trabajo forzoso", Relaciones Laborales n. ${ }^{1}$, quincena del 1 al 15 de enero 2011, año 27, tomo 1, 3-16.

Rojo, Eduardo (2014): «Nueva esclavitud y trabajo forzoso. Un intento de delimitación conceptual desde la perspectiva laboral. (El trabajo, sus presupuestos sustantivos y la dignidad humana)», ponencia presentada al "Congreso jurídico internacional. Formas contemporáneas de esclavitud», Granada, 2014 (http://www.slideshare.net/erojotorrecilla/ponencia-granada-342014).

Rubio Lara, Pedro Ángel y Pérez Albadalejo (2016): «El delito de trata de seres humanos en el derecho penal español: problemas e intentos de solución», Revista Aranzadi Doctrinal, n.o. 7, 2016, 207-250.

Salas Porras, María (2014): «Trabajador esclavo y contrato de esclavo: configuración jurídica", Revista Critica de Historia de las Relaciones Laborales y de la Politica Social.

SANZ, Gloria (2007): «Trabajos forzados, economía de guerra y empresa durante el nacionalsocialismo: un breve balance de recientes investigaciones en Alemania» en Gastón Aguas, J. M.y Mendiola Gonzalo, F. (Coord): Los trabajos forzados en la dictadura franquista: Bortxazko lanak diktadura frankistan, Instituto Gerónimo de Uztáriz - Memoriam Bideak. 
Villacampa Estiarte, Carolina (2011): El Delito de trata de seres humanos: una incriminación dictada desde el derecho internacional, Cizur Menor (Navarra)

Villacampa Estirare, Carolina (2012): «El delito de trata de seres humanos en el Código Penal Español.», Coediciones-Cívitas. Nuevos retos en la lucha contra la trata de personas con fines de explotación sexual (BIB 2012\1147 Editorial Aranzadi, S.A.U., Enero de 2012).

Vives, Juan Luis (2000): Tratado del socorro de los pobres, Ministerio de trabajo y Asuntos Sociales, 2000 (edición semifascimil de la edición castellana de 1781).

Wachsmann, Nilokaus (2015): Historia de los campos de concentración, Critica, Barcelona

WALK FREE FOUNDATION (2016): The global Index of slavery, Australia.

Weissbrodt, David and Anti-Slavery International(2002): La Abolición de la Esclavitud $y$ sus Formas contemporáneas, Oficina del Alto Comisionado de las Naciones Unidas para los Derechos Humanos, Nueva York y Ginebra.

Williams, Eric (2011): Capitalismo y esclavitud, Traficante de sueños, Madrid (1. a de. 1944).

\section{Sitios de ONGs}

Amnisty International «QATAR 2015/2016» en https://www.amnesty.org/es/countries/ middle-east-and-north-africa/qatar/report-qatar/

Anrti-slavery org, "What is modern slavery», http://www.antislavery.org/english/slavery_ today/what_is_modern_slavery.aspx

Free the slaves «Slavery is everywhere» http://www.freetheslaves.net/about-slavery/slaverytoday/

Ong Migrants rights «Understanding Kafala: an Archaic law at cross purposes withmodern development» (https://www.migrant-rights.org/2015/03/understanding-kafalaan-archaic-law-at-cross-purposes-with-modern-development/

50 FOR FREEDOM Nueva esclavitud http://50forfreedom.org/es/

\section{Audiovisuales}

Pollard, Sam (2012): Slavery by another name, PBS, http://www.pbs.org/tpt/slavery-byanother-name/watch/

DuVernay, Ada (2016): 13th, Netflix

\section{Mass Media}

Arrizabalaga, M. (2012): «Esclavos en la España del siglo XXI». $A B C, 21 / 12 / 201$, http:// www.abc.es/sociedad/20121202/abci-esclavos-espana-siglo-201211281343.html.

BBC NEWS (20I6): "ChILD REFUgEes IN TURKey MAKING CLOTHES FOR UK SHOps», $B B C 24.10 .2016$.

DeARden, Lizzie (2016). "Refugees being forced into «modern slavery» by people traffickers before attempting deadly journey to Europe», The independent, 24.10.2016.

Espinosa, Angeles (2016): "La quiebra de empresas saudíes deja a miles de inmigrantes atrapados», El Pais, 12.09.2016

Gibson, Owen (2016): «Fifa faces legal challenge over Qatar migrant workers», The Guardian, 10.10.2016 
Khan, Azfar (2014): "Why it's time to ends the kafala», The Guardian, 26.02.2014.

Lово, José L. (2011): "Brasil acorrala a Inditex: detectados otros 30 talleres de "esclavos" vinculados a Zara", El Confidencial, 19.08.2011.

Lово, José L (2012): "Trabajo esclavo en la India: tres empresas españolas están incluidas en la "lista negra"”, El Confidencial, 23.02.2012.

PurI, Kavita (2014): «Switzerland's shame: The children used as cheap farm labour», $B B C$ news, 29.10. 2014.

Tribuna de Valladolid (2016): «Liberan a 33 ciudadanos búlgaros que vivían en condiciones de esclavitud en Valladolid», Tribuna de Valladolid, 2.11.2016. 